\title{
Mercado, élite e institución: el Consulado de comercio de Guadalajara y el control corporativo de las importaciones en el mercado interno novohispano ${ }^{1}$
}

\author{
Para Andrés Orrego, \\ maestro que me abrió la puerta \\ al estudio de la historia.
}

En la ciudad de Guadalajara, la tarde del 11 de julio de 1791, medio centenar de los más notables comerciantes de la región, que se hallaban reunidos en las casas consistoriales, se constituyeron en Junta General de Comercio de la ciudad. Presidida por el alcalde más antiguo, regidor perpetuo y alférez real, don Juan López Portillo, los reunidos convinieron en la "necesidad que havía de que se estableciese en esta capital el Real Tribunal del Consulado y Universidad de Mercaderes en la forma en que lo está la de México". ${ }^{2}$ Para su negociación, acordaron nombrar a don Ignacio Estrada ${ }^{3}$ y a don Juan José Cambero ${ }^{4}$ como sus apoderados ante el intendente, el virrey y la Corte de Madrid, a efecto de que "hagan cuantas diligencias dicte la prudencia y la justicia para su consecución [...]".

1 Agradezco los pertinentes comentarios de Bernd Hausberger, Eulalia Lahmeyer, Carlos Marichal, Clara Elena Suárez y Guillermina del Valle.

2 AGI, Guad. 314, f. 2.

3 Un comerciante criollo, de 55 años hacia 1791; nacido en la capital y emigrado a Guadalajara se casó con doña Josefa Porres Baranda, acaudalada criolla del poderoso clan familiar Porres Baranda. Su vínculo con el clan lo llevó a ser el agente financiero de su suegro, concentrándose en los negocios agrícolas y descuidando sus giros en el comercio: su prestigio y relaciones entre la élite le conquistaron, seguramente, su lugar en la gestión del consulado (Lindley 1987: 106-112; Van Young 1989: 143-146).

4 Un comerciante vasco de 38 años, también casado con una criolla, doña Marcela de Castro, y alcalde ordinario del Cabildo de la ciudad. Cambero habría de tener un papel central en el nuevo consulado. 
La iniciativa para la fundación del Consulado de comercio de Guadalajara respondió, aunque tardíamente, a las reformas orientadas a la reglamentación del libre comercio y, particularmente, a la recomendación del virrey Revillagigedo de reducir el poder interno del Consulado de la ciudad de México, transformando el mercado oligopólico tradicional en un mercado multipolar, con mayor competencia entre los grupos de comerciantes y beneficios fiscales adicionales. ${ }^{5}$

En Guadalajara, la coyuntura de prosperidad iniciada hacia la década de 1770 había creado condiciones propicias para el desarrollo de un dinámico mercado regional en torno a la capital, complementado por una corriente de demanda de productos agropecuarios, artesanales e insumos para la minería del reino que fortalecieron sus lazos de mercado e intereses comerciales (Van Young 1989 [1981]: 55-116; Ibarra 2000b: 77-120).

La convergencia entre iniciativas de funcionarios virreinales, en particular las del intendente don Jacobo Ugarte y Loyola, y la perspicacia de comerciantes provinciales, generaron las condiciones propicias para gestionar los informes y dictámenes favorables a la iniciativa de un nuevo consulado. ${ }^{6}$ Los apoderados, Estrada y Cambero, dirigieron al intendente una solicitud para que tuviera a bien apoyar el proyecto "recomendándolo eficazmente a Su Majestad", con el debido respaldo de otras autoridades como la Real Audiencia, el Obispo, el Ayuntamiento y los “[...] demás que tenga Vuestra Señoría por convenientes para lograr la real gracia de la erección de un consulado bajo el mismo pie y reglas que el de México, concediéndole por territorio el de la Real Audiencia y su espreso real permiso para formar ordenanzas que no se observaran sin su previa real autorización"? Más tarde, como resultado de las gestiones del intendente Ugarte y Loyola,

5 Nos referimos a la implementación del Reglamento de Libre Comercio de 1778, y particularmente al real decreto, del 28 de febrero de 1789, que retiró el monopolio del tráfico americano a Cádiz, debilitando, correlativamente, la estructura monopólica de los consulados americanos para la década de 1790. Véanse los trabajos de Pérez Herrero (1987) y la interpretación de Bernal (1987).

6 El 20 de agosto de 1791, los apoderados dirigieron una misiva al intendente Ugarte y Loyola, en la que hacían valer sus argumentos para solicitar la erección del Consulado, así como su expresa ayuda para lograr esta encomienda; AGI, Guad. 314, f. 18.

7 Véase Gálvez (1996: 200-224) 
vendrían los apoyos de las autoridades locales y de un grupo de vecinos notables de reconocido prestigio y poder. ${ }^{8}$

Desde que se constituyó la mencionada Junta General de Comercio hasta que se obtuvo la real cédula de erección del Consulado, un lustro más tarde, la gestión política de los comerciantes de Guadalajara creó una red de intereses que se tradujo en una gestión colectiva orientada a la reforma de los mecanismos institucionales del mercado. ${ }^{9}$ El proyecto de erigir un cuerpo autónomo en Guadalajara hubo de enfrentar, naturalmente, la oposición del Consulado de comercio de la ciudad de México. ${ }^{10}$

\section{El problema: representación corporativa y gestión institucio- nal de la élite comercial}

Los criterios que dieron sustento al proyecto de un nuevo consulado de comercio en Guadalajara fueron, claramente, orientados en una dirección sustantiva: disminución de los costos de negociación resultantes de las frecuentes defraudaciones, quiebras e incumplimiento de contratos. Los comerciantes lo glosaron así:

No se ve que siendo el principal instituto de estos Tribunales el arreglo de los Individuos del comercio, la observancia de buena fe, evitar, en lo posible las Quiebras fraudulentas, reparar, por medios de equidad, las inculpables, cortar Pleitos, y componer las diferencias breve y sumariamente, a verdad sabida, buena fe guardada y administrar con la debida pureza lo destinado a Fondos Públicos del mismo Comercio, no pueden dejar de ser utilísimos los Consulados, y estimarse realmente por unos

$8 \quad$ Entre los testigos estaban los notables hacendados y comerciantes don José María Porres Baranda, don Manuel Calixto Cañedo y don Ignacio Basauri, capitán de dragones de San Luis Colotlán, además de don Agustín Tamayo, juez real de la Audiencia, los religiosos bachiller don José María Ubiarco, el presbítero don Pedro Cantú y el bachiller don Felipe Neri Pérez Vallejo del Oratorio de San Felipe Neri, don Gregorio Pérez, capitán de granaderos del regimiento provincial, don José Dávalos, teniente coronel de las milicias de Tepic y un documentado parecer de don Juan José de la Hoz, administrador general de alcabalas de Guadalajara; AGI, Guad. 314.

9 Representación del Cabildo e individuos del comercio de Guadalajara, solicitando la instalación de un consulado y universidad de comercio en Guadalajara, 12 julio de 1791, AFRAG, libro 287.

10 Sobre el papel del Consulado de comercio de México en el control del mercado monopólico y su resistencia a los consulados nuevos, véanse los trabajos de Valle Pavón (1997 y 2000), y desde la perspectiva de Guadalajara, Gálvez (1996: 4556). 
tribunales y Cuerpos que afiancen la felicidad de las Capitales y muchos Lugares de su comprensión. ${ }^{11}$

Asociado a esa función, esencial al nuevo cuerpo, se advertía la importancia de lograr la reglamentación de los costos de circulación, tanto los fiscales como los derivados de malas comunicaciones e incertidumbre en los intercambios a distancia, así como de costos de representación institucional de los intereses colectivos que demandaba una corporación consular.

Estas iniciativas, y las características formales del nuevo cuerpo consular, dieron un giro decisivo a la organización interior del comercio: tejieron una red territorial de representaciones, delimitaron los intereses colectivos del comercio regional, instrumentaron mecanismos de gestión y representación, crearon mecanismos de resolución de conflictos, orientaron el gasto fiscal en ingresos al comercio y desplegaron una estrategia de mejoras materiales a la infraestructura del mercado -caminos, puentes, "cajones" para las ferias, entre otros-y promovieron un acuerdo institucional en los contratos y su cumplimiento, asegurando con ello los derechos de propiedad. En suma, el protagonismo inicial de los comerciantes, como actores económicos de esta nueva trama, dotó a la institución consular de una gran capacidad de gestión del cambio económico.

Según su cédula fundacional, siguiendo las ordenanzas de Bilbao, el consulado debería desempeñarse como cuerpo consiliario particular de los individuos del comercio, atendiendo a un doble carácter: como institución judicial, debía orientarse a resolver las disputas entre sus agremiados, gozando de autoridad para imponer sus decisiones judiciales; como una instancia de gestión y representación, habría de asumir los intereses del comercio de Guadalajara y su territorio jurisdiccional ante el monarca y su Real Hacienda, gestionando favores y concesiones. $^{12}$

El Tribunal del Consulado estuvo conformado por un prior y los dos primeros cónsules electos, con sus respectivos tenientes; en ellos descansaba la responsabilidad de resolver sumariamente las disputas "en estilo llano, a verdad sabida y buena fe guardada", auxiliados por

11 Representación [...], 1791, f. 180, AFRAG, libro 287.

12 Real cédula de erección del Consulado de Guadalajara, 8 de junio de 1795, Aranjuez, AGI, Guad. 526 (impreso); Cruz Barney (2000: 83-88). 
un asesor letrado, dos alguaciles y un escribano. ${ }^{13}$ En su caso, los diputados designados por ese Tribunal en el territorio jurisdiccional tenían la atribución de conocer, resolver o encauzar conflictos entre particulares en sus respectivas localidades. Se hacía expresa prohibición a la intervención de cualquier abogado por las partes, contando con la venia del asesor letrado de la Audiencia para el fundamento judicial de cada resolución. ${ }^{14}$

La Junta de Gobierno, por su parte, se componía de los miembros del Tribunal y de nueve consiliarios y un síndico, con sus respectivos tenientes, igualmente electos de manera indirecta. El conjunto de consiliarios fungía como un cuerpo consultivo y deliberativo de negociaciones e iniciativas favorables al comercio en su conjunto. En la administración del Consulado, intervenían un secretario, un tesorero y su contador. ${ }^{15}$ Además, el Consulado contó, desde sus primeras gestiones, con un apoderado en Madrid, encargado de dar curso a peticiones y réplicas, gestiones políticas y negociaciones discrecionales. ${ }^{16}$

En los hechos, sus funciones sustantivas se complementaron con el tejido de una red de diputaciones locales que permitieron a la corporación lograr una cohesión institucional entre los mercaderes de Guadalajara y los comerciantes prominentes del reino, que fungían como corresponsales de la institución. Además, se aprovechó de una red constituida de administradores de alcabalas, encargados de la recaudación de la avería consular, con descuento de un porcentaje sobre la renta total recaudada (ver esquema 1).

El poder institucional del Consulado descansaba, sin embargo, en la cúpula organizativa del mismo, esto es, en el prior y los cónsules que conformaban el Tribunal, quienes a su vez constituyeron una minoría dinámica en la estructura de representaciones consulares. Se trata de una suerte de élite afianzada en el control de las funciones sustantivas del Consulado: la justicia y la autoridad corporativa del Tribunal.

13 Don José Antonio Mallén fungió como escribano y como alguaciles, don Juan Martínez del Campo y don Hipólito Gutiérrez.

14 Así, también, el asesor letrado para pleitos mercantiles fue don Francisco Antonio de Velasco.

15 Don Manuel Pereda se desempeñó como secretario, don Manuel de las Heras como contador, don Joaquín Venel y Liaño como tesorero.

16 El apoderado en Madrid, fundamental a todas las negociaciones institucionales, fue don Miguel Ortiz de Rosas. 


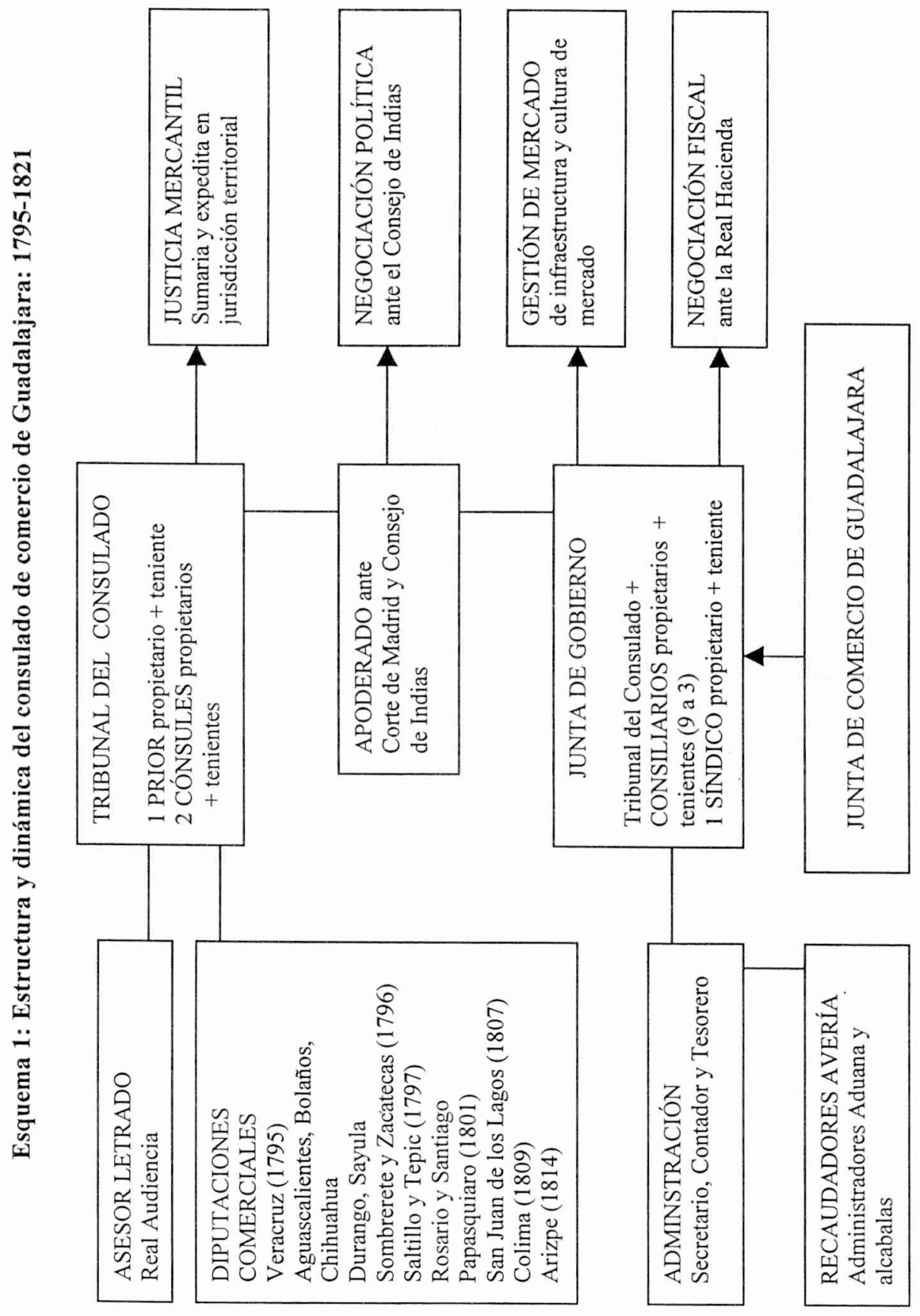


En el desempeño institucional del Consulado, las funciones relevantes de representación, gestión y negociación eran cumplidas por ese grupo. Veintiocho comerciantes que ocuparon más del $40 \%$ de los cargos electos entre 1795 y 1820 : la totalidad de los priores, propietarios y tenientes, así como los cargos de cónsules propietarios y más de la mitad de los cónsules tenientes y síndico propietario. Estos fueron quienes estuvieron en la cúpula institucional del cuerpo, el Tribunal consular, y los que hicieron del control institucional su identidad corporativa (cuadro 1).

Cinco de éstos concentraron, entre la fundación del Consulado y mediados de la década de 1810 , más de la mitad de las nominaciones a prior, asimismo fueron repetidamente electos para cónsules y consiliarios. Entre los de mayor relevancia, porque muestran un patrón ejemplar de participación en el Consulado, pueden mencionarse a don Juan José Cambero; ${ }^{17}$ don Antonio Pacheco Calderón, ${ }^{18}$ don Juan Manuel Caballero, ${ }^{19}$ don Eugenio Moreno de Tejada ${ }^{20} \mathrm{y}$ don Guillermo Anto-

17 Cambero, nombrado representante de la Junta de Comercio de 1791, participó en las negociaciones para la erección del mismo. Fue electo, sucesivamente, entre 1795 y 1802, como cónsul propietario (1795), consiliario suplente (1797), prior teniente (1800), cónsul propietario (1802). Sería prior propietario, por primera vez en 1809 y vivió la crisis de la guerra de Hidalgo, sucedido por don Antonio Pacheco Calderón en 1811, volvió al cargo como teniente en 1813 y nuevamente propietario en 1817. Es decir, entre la fundación del Consulado y 1819 prácticamente siempre estuvo presente en la vida del mismo. Su caso, destaca la carrera de ascenso firme y pausado en la jerarquía del cuerpo consular.

Un conocido comerciante santanderino, firmó la representación para la fundación del Consulado, en 1791, y fue nombrado consiliario teniente en 1795. No seria hasta 1800 que cobraría importancia al ser electo prior propietario, así también para el critico año de 1811 y finalmente en 1818 sería electo nuevamente como consiliario propietario. Antonio Pacheco, así como su hermano Manuel, seguirían el derrotero de ingreso a la élite regional casando con criollas, del clan Del Río, estableciendo alianzas de propiedad y herencia, adquiriendo haciendas y refaccionando de crédito a comerciantes y hacendados (Lindley 1987: 116-125).

Un vasco que hacia 1791 se desempeñaba como cajero de don Juan Ángel Ortiz, miembro fundador del Consulado, habría de casar más tarde con doña Juana de Dios Fernández de Barrena, del clan del marqués de Pánuco Francisco Xavier Vizcarra, y poco después iniciaría su ascenso en el Consulado como síndico teniente en 1799 , prior teniente en 1802 , cónsul teniente en 1809 y propietario en el aciago año de 1811 , fue más tarde prior teniente en 1817 y hacia 1819 logró ser propietario. Durante más de 20 años se mantuvo vinculado al Consulado hasta llegar al cargo de mayor relevancia. Sus negocios agrícolas, el comercio de importación e inversiones mineras le dieron un connotado lugar en la élite regional (Lindley 1987: 76 y 114; Van Young 1989 [1981]: 159 y 179-180). 
nio Caserta y Dans Stuart, barón de Santa Cruz. ${ }^{21}$ En conjunto, los comerciantes mencionados destacan el modelo empresarial de una élite integrada en los negocios y en las relaciones interfamiliares que, además, encontraron en la corporación una representación institucional del mayor nivel e importancia para sus negocios. ${ }^{22}$

No obstante, aunque controlada por una élite, la institución consular operó como un agente institucional de los intereses colectivos de los comerciantes, estableciendo normas reglamentarias de negociación y cumplimiento, y asumiendo costos institucionales de organización, representación, cumplimiento y desarrollo del mercado, los cuales significaron una disminución de los costos privados de transacción, así como estableciendo normatividad y certidumbre en los contratos y negociaciones que tuvieron un efecto positivo en los beneficios privados y resultaron en una estructura de costos de negociación institucionales. Vale decir, aun siendo una institución de Antiguo Régimen, el Consulado cumplió funciones decisivas para el desarrollo del mercado moderno. ${ }^{23}$

20 Un comerciante riojano, de 36 años cuando firmó para la fundación del Consulado, del cual fue consiliario propietario por real cedula, en 1795. Casado con doña Josefa Sánchez Leñero, perteneciente al clan familiar de terratenientes, encontró su colocación en la élite a través de este conducto. Su hermano, José Prudencio, seguiría el mismo sendero al casarse con la hermana de su cuñada, doña Manuela Sánchez Leñero. Eugenio sería electo más tarde cónsul propietario, en 1799, y finalmente llegaría a la cúspide corporativa al ser electo prior propietario en 1805 (Lindley 1987; Van Young 1989 [1981]: 166-172).

21 Marqués de Mezquital, minero zacatecano avecindado en Guadalajara, casó con doña Ana Josefa Cañedo estableciendo vínculo con la familia de don Manuel Calixto Cañedo, quizá la más poderosa entre los terratenientes regionales. El caso del barón de Santa Cruz revela la importancia social de la pertenencia al Consulado: sus negocios y estirpe dieron lustres a la corporación, pero también le trajeron beneficios al minero metido a comerciante, desde su elección como cónsul propietario, en 1797, hasta que lograra ser nombrado prior propietario en 1813 (Van Young 1989 [1981]: 175-176).

22 "A principios del siglo XIX", sostiene Lindley (1987: 84-85), "la élite de Guadalajara no podía dividirse convenientemente entre comerciantes, terratenientes, mineros, criollos o peninsulares. Una sola élite residente en la ciudad dominaba la vida política, comercial y agrícola de la región".

23 Véase el análisis cuantitativo de los costos institucionales de transacción en Ibarra (2000a: 243-260). 


\section{La avería y la territorialidad exterior de Guadalajara}

Desde su fundación y como una gracia real para el sustento de los nuevos consulados de comercio recién creados en Veracruz y en Guadalajara, les fue concedido el derecho de recaudar la avería ${ }^{24}$ cobrada a los cargamentos descendidos en los puertos y destinados para su venta al distrito de su competencia, que hasta entonces se mantuvo adjudicado, en exclusividad, al Consulado de Comercio de la ciudad de México. ${ }^{25} \mathrm{Al}$ cumplir con la función de fiscalización corporativa del tráfico importado que circulase por su territorio, el Consulado tenía en sus manos una información de mercado de la mayor importancia en una situación de competencia entre corporaciones, grupos de comerciantes y negociantes locales, toda vez que se podía advertir el comportamiento de la demanda de los principales centros de consumo en el comercio de larga distancia.

Por nuestra parte, mediante este derecho, podemos establecer grosso modo el origen, valor, calidad y destino interior de los cargamentos bajados en los principales puertos del reino -Veracruz, Acapulco y San Blas-, así como ubicar a los consignatarios de las mismas, y con ello determinar vínculos entre agentes y comerciantes de los puertos, con los compradores del interior. Asimismo, dicha fuente permite reconstruir la red de circulación de importaciones averiadas en los puertos con los lugares de expendio y distribución del interior, tanto como la red de intereses implicados en la distribución de importaciones en el territorio.

24 Esta figura fiscal, del siglo XVI temprano, fue modificando su función y gravámenes hasta formar parte de los recursos regulares de los cuerpos americanos de comercio, cobrándose una "avería de tierra" que gravaba a las importaciones internadas al reino, y sus recursos destinados a sufragar gastos y fomento del comercio americano. Véase Céspedes del Castillo (1945: 3-4).

"Será fondo del Consulado [de Comercio de Guadalajara] el derecho que le concedo de avería [...]. Por derecho de avería cobrar medio por ciento sobre el valor de todos los géneros frutos y efectos que se extraigan e introduzcan por mar en todos los puertos de su distrito. También cobrará el medio por ciento de todos los frutos y géneros que habiéndose desembarcado en el puerto de Veracruz se conduzcan con guías de su Aduana a todas las Provincias del distrito de este nuevo Consulado, y otro medio de todos los caudales y efectos que procedentes de las mismas Provincias se introduzcan y embarquen para estos Reinos en el citado puerto de Veracruz, cuyo Consulado no debe cobrar cosa alguna de lo que se dirija o venga del distrito del de Guadalajara, [...]"; Real cédula [...], cláusula XXI, AGI, Guad. 526. 
El asiento del cobro de avería, que debía efectuarse en las aduanas al tiempo de cubrir los derechos reales, se enteraba a los administradores del Consulado por cuenta separada para el propio cuerpo, entregado el líquido mediante libranzas, sin manejarse en ramo alguno de la Real Hacienda, ya que la corporación rendía cuentas directamente al monarca. $^{26}$

El cómputo de los derechos recaudados es, por tanto, un aspecto importante de la información consular, ya que a través de estos registros es posible calcular no solamente los volúmenes del comercio legal, sino también identificar su calidad. De esta manera, los libros de contabilidad consular nos refieren, por lo menos, tres aspectos relevantes con relación a la recaudación de la avería: primero, el cálculo de los importes globales traducidos a una dimensión económica nos permite estimar el valor del comercio averiado; segundo, la distribución espacial de la recaudación del derecho nos señala la red primaria de circulación interior de importaciones, y; tercero, la diferenciación de los ramos de recaudación entre frutos y efectos del país, españoles y extranjeros nos marca claramente la composición del tráfico averiado. $^{27}$

Así, entonces, por el cobro de avería es posible calcular que en el distrito del Consulado de Guadalajara ingresaron, entre septiembre 1795 y diciembre de 1818 -exceptuando el año de 1806-, mercancías de importación por un valor aforado superior a los 75 millones de pesos, de los cuales es posible conocer su composición en aquellas

26 El derecho a cobrar se asentaba en el artículo XXXI de la real Cédula, mientras que en la definición de su administración se especificaba que "se entenderá el Consulado con los Administradores; y éstos sin más orden ni disposición deberán entregar su producto, siempre que se les presenten libranzas del Prior y Cónsules intervenidas del Contador. Bien entendido que este ramo no debe comprehenderse [sic] en ninguna de las cuentas de mi Real Hacienda, y que las libranzas del Prior y Cónsules, unidas a los respectivos registros, serán el justificativo de su data y solvencia en esta parte"; Real cédula [...], item XXXII, AGI, Guad. 526.

27 Los libros analizados comprenden un amplio periodo de la vida institucional del Consulado, inicia con la primera cuenta de septiembre de 1795 a agosto de 1796 y concluye en diciembre de 1818, excluyendo el año de 1806 que no aparece en los registros del AGI. Las 22 cuentas presentan, sin embargo, una irregular carga de información debido quizás a la modificación del método de asentamiento, que eliminó progresivamente el acompañamiento de comprobantes de cargo para ser reemplazado por estadillos consolidados de cada administración, siguiendo el método de partida doble. 
que representaron 69,7 millones de pesos: más de una tercera parte fueron efectos del país, esto es, más de 26,5 millones de pesos; otro tanto de efectos extranjeros, alrededor de 26 millones, y casi un cuarto del total en efectos españoles, más de 16,4 millones (Ibarra 1996: 7-37).

A este nivel ascendieron, según la fuente consular, los importes nominales del tráfico introducido legalmente y fiscalizado por el Consulado, lo que representó un ingreso superior a $376 \mathrm{mil}$ pesos, solamente por concepto de avería. Como puede advertirse, el manejo de las cuentas exigía cierto cuidado y una eficiente red de recaudación, así como una competente contabilidad que impidiera fugas financieras en administraciones distantes a la sede del Consulado, principalmente en puertos de entrada. De la misma manera, era importante que la contabilidad estableciera muy puntualmente la parte que correspondía a cada uno de los tres consulados del reino, de acuerdo a su particular territorialidad: Veracruz, México y Guadalajara.

En el caso del Consulado de Guadalajara, según se estipuló en la real cédula que le dio origen, su jurisdicción fiscal coincidía con los límites de su Audiencia, con lo cual se dotó a los comerciantes tapatíos de una amplísima territorialidad que comprendía la costa oeste del Pacífico y el cinturón minero de Zacatecas y San Luis Potosí, así como el dilatado espacio septentrional novohispano a lo largo del camino de Tierra Adentro, en sus dos cauces, el oriental hacia Saltillo y el occidental por Durango y Chihuahua.

Si bien la amplitud territorial es importante, conviene distinguir los segmentos de esta espacialidad mercantil fiscalizada por el cuerpo consular. Por tanto, hay que tener en cuenta una doble perspectiva en el cobro de la avería: primero, estimar la recaudada en los puertos de entrada sobre mercancías que, con destino a distintos puntos del territorio del Consulado, eran gravadas antes de ingresar al espacio consular; y, segundo, el cobro del derecho en centros de distribución y expendio al interior del territorio consular. En ambos casos, los límites recaudatorios nos revelan un amplio espacio económico referido al elemento integrador del Consulado que, para efectos analíticos, podríamos dividir de acuerdo a su naturaleza económica en el esquema de organización del mercado (cuadro 2).

Por otra parte, es importante recordar que la organización del espacio mercantil del Consulado se vio reforzada no solamente por la 
fiscalización de las rutas de circulación, como hemos explicado antes, sino también por la instalación de diputaciones comerciales, que gozaban de una amplia representación ante el cuerpo consular. Ello significó, en un sentido institucional, la extensión de las funciones judiciales atribuidas al cuerpo consular para la resolución de controversias mercantiles, pero también un canal para las funciones de gestión, negociación y representación de un amplio territorio. ${ }^{28}$

Finalmente, un aspecto a subrayar es la instalación de agentes encargados de supervisar el cobro de avería y deslindar la competencia de derechos con otros cuerpos consulares, en particular en los puertos de entrada al reino. Desde luego que Veracruz fue el que gozó de mayor importancia, por lo menos hasta 1810; pero también se dispuso de agentes en otras entradas marítimas, como Acapulco y el propio San Blas, convirtiéndose éste último en el principal fondeadero marítimo regional, una vez rota la comunicación terrestre con el puerto jarocho a consecuencia de la inseguridad de los cargamentos en los caminos que acompañó a la guerra insurgente.

\section{La red de distribución regional a larga distancia: la avería de 1795-1796}

Como es sabido, por el puerto de Veracruz ingresaba el grueso del comercio ultramarino al reino. ${ }^{29}$ Desde allí se estableció un rígido control sobre las importaciones y se surtía al comercio interior, despachándose los cargamentos a la capital del reino y a otras plazas más distantes. El control institucional del tráfico ejercido por los comerciantes mayoristas de la ciudad de México, con el poderoso instrumento del Consulado, había sido una constante hasta la adopción del libre comercio y la erección de los nuevos consulados provinciales (Gálvez 1996: 49-51 y 208-212).

Según la real cédula, en su item $\mathrm{X}$, se estableció como territorio judicial el de la Audiencia de Guadalajara y "para mayor comodidad de los litigantes tendrá Diputados en aquellos [sic] puertos y lugares de más comercio, donde parezcan necesarios, que conozcan con igual jurisdicción de los pleitos [ $\mathrm{sic}]$ mercantiles en dichos puertos y lugares. [...] Los puertos y lugares donde convenga nombrar Diputados, se señalarán por el Comandante General a propuesta del Consulado, luego que se haya establecido: y se me dará cuenta de ello para su aprobación"; Real cédula [...], f. 10-11, AGI, Guad. 526.

29 Véanse los trabajos de Souto Mantecón (2000 y 2001) y García de Léon (en este volumen). 
Un primer resultado, evidente para todos los consulados del reino, fue la nueva situación de compartir la administración de los derechos de avería con relación a los distintos territorios de competencia, como hemos explicado antes. La administración de este derecho supuso una nueva organización de la fiscalización de importaciones de acuerdo al nuevo esquema territorial de soberanías comerciales. De esta manera, el Consulado de comerciantes de Guadalajara estableció en los puertos de entrada, principalmente en el de Veracruz, administradores encargados de supervisar el despacho de cargamentos a su territorio, así como de fiscalizar los envíos de mercancías o caudales que salían de éste. $^{30}$

Dos aspectos son relevantes a los intereses del consulado y a la medición del comercio interior de importaciones: primero, la efectiva graduación del valor de los cargamentos para el cobro del medio por ciento que correspondía a las arcas consulares y, segundo, la escrupulosa distinción de los derroteros del comercio despachado desde el puerto hacia el territorio jurisdiccional del Consulado. Esta doble cualidad de los registros de la avería hace extraordinariamente relevante su asiento contable para conocer el esquema de distribución interior de importaciones.

Como hemos adelantado, el territorio jurisdiccional del Consulado comprendió prácticamente el gran norte novohispano en un arco geográfico que iba desde la costa occidental del Mar del Sur en Colima, hasta la desembocadura del Pánuco en el Barlovento. El arco interior cubría los contornos de la intendencia de Guadalajara, el cinturón minero central de Zacatecas y San Luis Potosí, así como el septentrión novohispano en sus vertientes interiores de Tierra Adentro y la costa occidental de la intendencia hasta las Californias. Como se apreciará, se trataba de un enorme territorio que combinaba una diversidad de rutas y mercados regionales, comprendidos todos en las fronteras jurisdiccionales de la Audiencia de Guadalajara.

Esta peculiaridad, sancionada en la real cédula de erección del Consulado, le permitió a los comerciantes de Guadalajara tener un

30 De Veracruz, los informes venían de la pluma de don Francisco Antonio de Agudo, administrador de la Real Hacienda en aquel puerto. Desde Tepic se glosaba lo que se comerciaba por San Blas, por mano de don Juan Manuel Siniaga, administrador de rentas unidas del partido. En Acapulco se comisionó a don Lorenzo Liquidano. 
amplio cómputo de la introducción y circulación interior de importaciones y productos americanos. Así, tanto los registros de puertos y ciudades, como de haciendas de minas y campo, al igual que las ferias, quedaban asentados en la contabilidad fiscal del Consulado, toda vez que las mercancías que ingresaban a su territorio estaban obligadas a cubrir el derecho mencionado, aun cuando provinieran de la ciudad de México y hubieran satisfecho el derecho en los puertos de entrada.

Gracias a estos registros, precisamente, hemos podido dibujar las trayectorias del tráfico averiado en un vasto territorio y adelantar algunas hipótesis sobre el control del comercio de Guadalajara respecto a lo que circulaba en este amplio espacio económico.

El examen detallado del primer ejercicio de fiscalización en favor del Consulado de Guadalajara, entre septiembre de 1795 y agosto de 1796, arrojó un importante registro de la mano de don Manuel de las Heras, contador de ese Consulado en Veracruz: un cómputo sistemático de todos los despachos desde el puerto al territorio jurisdiccional del Consulado así como de los envíos a la península provenientes de él. $^{31}$

Según este libro de registro, se consignaron 708 partidas de las cuales 646 aludían a internaciones y 62 correspondían a exportaciones, 56 de éstas últimas en plata por cuenta de particulares y el resto en productos americanos, entre ellos búcaros de Tonalá. El valor total estimado, a partir del porcentaje del derecho, ascendió a más de 3 millones de pesos: 2,9 millones correspondientes a importaciones y $160 \mathrm{mil}$ pesos a exportaciones.

De los despachos del puerto al vasto territorio consular, 604 guías se ampararon bajo la leyenda de "efectos", sumando más de 2,9 millones de pesos. Eso significa que sobre el $94 \%$ de los despachos carecemos de detalles específicos sobre sus mercancías. Sin embargo, aunque constituya una referencia marginal, conviene anotar algunos datos sobre el tipo de comercio que se despachaba de Veracruz y pagaba avería, especialmente de vinos importados (de Rioja, Málaga o Jerez), tabacos labrados o en polvo y una variedad de ropa, textiles,

31 El cuaderno correspondiente a Veracruz se encuentra en las Cuentas generales que del primer año de su establecimiento remite el Consulado de Guadalajara de Indias a Su Magestad para su examen y aprobación, AGI, Guad. 529. 
sombreros, seda, impresos y libros, metales no preciosos (cobre y acero) hasta vidrios y vasos de cristal.

La importancia de la fuente radica, no obstante, en otras cualidades informativas, a saber: la determinación de valores de comercio y sus puntos de destino en el territorio consular, así como la pirámide de intereses involucrada en el tráfico que partía de Veracruz. Lo más relevante, para el análisis que nos proponemos realizar, está precisamente en la geografía de la circulación develada por esta contabilidad consular. $^{32}$

De esta manera, hemos podido establecer en el escrutinio de los despachos 84 destinos del comercio averiado en el territorio consular de Guadalajara, aunque carecemos de información precisa sobre cerca del $30 \%$ del valor de las remisiones, asentadas como "a varios destinos", pero que sin duda se dirigían al amplio territorio consular. Por otra parte, identificamos que 60 despachos a España se dirigían a Cádiz como destino y otros dos a Sevilla y Santander.

Lo más relevante es, desde luego, la circulación interior del reino: entre los principales destinos del comercio en derechura estaban, en ese orden de importancia, las ciudades mineras de Zacatecas, Sombrerete, San Luis Potosí, Durango y Parral; así como los reales mineros de Catorce, Bolaños, Guarisamey, Álamos, Rosario, Loreto y Avinito. La feria de San Juan de los Lagos fue, desde luego, uno de los destinos de la mayor importancia en el tráfico a distancia. Además de Guadalajara, las principales consignaciones al mercado regional contemplaron Aguascalientes, Tepic, Lagos, Etzatlán, La Barca y Sayula. Asimismo, se consignaron envíos a once haciendas de campo y, por lo menos, a una veintena de reales de minas de menor importancia dispersos en el territorio.

Por su parte, los embarques alcanzaron los destinos septentrionales de Saltillo y Chihuahua por el camino de Tierra Adentro, mientras que por la ruta meridional del Pacífico son de notar, por el valor de sus envíos, los destinados a Tepic, Culiacán, Sonora, Arizpe y Horcasitas.

Aunque la diversidad de destinos nos muestra la amplitud del tejido comercial surtido desde Veracruz, es notable la concentración del valor en una veintena de plazas, ya que sólo en éstas se destinó en de-

32 Una apreciación distinta, menos optimista, en el trabajo de Souto Mantecón (2001: 152-156). 
rechura más del $60 \%$ del valor total del comercio averiado, que sumadas al $31 \%$ que representaron los despachos a varios destinos, totalizan más del $90 \%$ del valor total (ver cuadro 4 y mapa 1 ).

Como se desprende de la organización de los datos referidos, son las ciudades del norte minero enlazadas por el camino de Tierra Adentro las de mayor importancia como centros de consumo y distribución, ya que sólo ellas concentraron un tercio del valor total averiado: Zacatecas $(13,2 \%)$, Sombrerete $(1,6 \%)$, Durango $(5,0 \%)$, Saltillo $(9,9 \%)$ y Chihuahua $(3,0 \%)$.

La feria de San Juan, como hemos anotado, fue el principal destino fuera del sistema urbano de comercio, más aún si consideramos la brevedad de su mercadeo y las características de la negociación en régimen de ferias, lo cual explica el alto valor promedio de sus despachos, superiores a los 16 mil pesos. ${ }^{33}$

Por el contrario, en el caso de Guadalajara es manifiesto que fue la plaza con mayor tráfico con el puerto, con 118 guías anuales, seguida de Zacatecas que llegó a 81. Mientras que para Guadalajara el promedio por despacho alcanzó los 1.200 pesos, en la ciudad minera cuadruplicó su promedio, a 4.800 pesos por guía. La desigualdad de los valores promedio sugiere ciertas diferencias en la naturaleza del comercio: una mayor frecuencia e integración en el de Guadalajara y un mayor valor en despachos episódicos hacia Zacatecas. ${ }^{34}$

Es preciso, no obstante, ordenar la diversidad de destinos de acuerdo a la propia organización del mercado interno novohispano y en atención a nuestro esquema explicativo de la vinculación de Guadalajara al mismo. De esta manera, una vez separadas las exportacio-

33 La feria anual se realizaba en la primera quincena de diciembre, con ocasión de la celebración religiosa a la Virgen de la Concepción, en el pueblo de San Juan. Según testificó el visitador Menéndez Valdez en 1793, durante la feria "[...] el concurso de gentes pasa de 35.000 almas [población superior a la capital de la intendencia] con la particularidad de que siendo el lugar muy corto [en] su población y terreno, todos se colocan, pero con la mayor estrechez". El mismo testigo, calcula el valor del comercio en más de un millón de pesos (500 mil en efectivo y 700 mil al fiado), muy por encima de los valores asentados en la contabilidad fiscal de la época (Menéndez Valdez 1983 [1793]).

34 "Pero si el monopolio se debilitó, no se abolió", sostiene Van Young (1989 [1981]: 156-157), "y la mayoria de los comerciantes de Guadalajara seguían negociando a través de casas comerciales de la ciudad de México, ya que no tenían ni las conexiones ni los medios necesarios para comerciar en forma directa con España". Nuestra impresión es otra, como se desprende los datos analizados. 
nes del tráfico interno, la salida de plata no se hizo en abono de los cargamentos despachados sino por consignaciones a particulares, lo cual supone que ésta correspondía a un circuito de transacciones distinto al de las mercancías.

Además, como ya lo hemos señalado, las rutas troncales del tráfico interior fueron una inequívoca forma de organización del mercado en el septentrión novohispano. De esta manera, resulta evidente para el amplio territorio del Consulado distinguir dos derroteros fundamentales: el camino de Tierra Adentro, considerando las regiones mineras a su paso, y el tráfico por el circuito transpacífico, dependiente del camino entre Guadalajara, Tepic y el puerto de San Blas. Ambas rutas, si bien de importancia variable, indican el trazado de las grandes avenidas septentrionales del mercado novohispano y por extensión de su demanda territorial (Serrera 1992: 46-50).

Adicionalmente, entre los mercados nucleares de mayor importancia figuran las capitales de territorios mineros, como Zacatecas, Durango y San Luis Potosí, pero también su entorno agrícola y de abasto. Otra consideración merecen los reales de minas que, aunque remotos, fueron centros de demanda que jalaron a los circuitos de circulación, sobre todo en momentos de prosperidad.

En el caso de la economía regional de Guadalajara, incluyendo a la feria de San Juan, hemos juzgado pertinente distinguir entre la demanda urbana de la capital y de su entorno regional, de su hinterland comercial, para completar el cuadro del sistema de mercados que hemos tratado de mostrar. ${ }^{35}$ De esta forma, el circuito de los negocios regionales comprende tanto el abasto a la capital como el despacho en derechura de mercancías a otras localidades, como Tepic, Lagos, La Barca, Etzatlán, Sayula y Colima, que cumplían funciones distributivas en su entorno inmediato.

Desde luego que hemos reconocido la importancia de la feria de San Juan, tanto para el tráfico regional como para la distribución a distancia, por ello es preciso hacer notar el valor de los despachos dirigidos directamente de Veracruz para aquella celebración.

35 Una aproximación a la feria de San Juan, desde la perspectiva de sus redes de aprovisionamiento y su impacto en la circulación interior, puede verse en Gálvez/Ibarra (1997: 581-616). 
Es así, entonces, que la sistematización de los registros de destinos cobra importancia para nuestros propósitos: la distribución de valores por circuitos de circulación, como se muestra enseguida, constituye su aspecto esencial.

De esta manera, tres son los segmentos fundamentales de la distribución desde Veracruz, ya que en conjunto suman más del $56 \%$ del valor averiado, a saber: el comercio septentrional por el camino de Tierra Adentro, el abasto de las minas del reino, en menor medida las regionales, así como la feria de San Juan de los Lagos.

Cada uno de estos circuitos tiene peculiaridades que es preciso reconocer. De esta manera, la ruta septentrional al cruzar longitudinalmente distintas regiones económicas combina el abasto de reales de minas, que responde básicamente a una demanda localizada y de alta liquidez, con la demanda de regiones de abasto a las minas, que expresan el dinamismo económico local, así como centros urbanos en expansión que suponen un variado y creciente consumo. Por tanto, resulta explicable que más del $43 \%$ de las guías despachadas del puerto haya seguido este cauce, sumando casi 1,2 millones de pesos, que representaron el $38 \%$ del valor averiado.

En el caso específico de la demanda minera, los 100 despachos dirigidos a centros de minas reflejan esta importancia, en mayor medida para las del reino ya que 91 de sus guías sumaron, prácticamente, 250 mil pesos. Ahora bien, en el caso de las remisiones a las minas regionales, 11 en total, se destaca que el importe promedio de los despachos rebasó al de las minas novohispanas, probablemente debido al momento de prosperidad comercial que vivía la región de Guadalajara y que tenía en sus minas un importante segmento de demanda.

En un sentido semejante, aunque a una menor escala, el despacho de mercancías a las haciendas de campo nos muestra la fuerza de la demanda rural que se hace presente en los circuitos de circulación: una quincena de despachos, a un promedio cercano a los 2 mil pesos, es una buena evidencia. Muy probablemente, su capacidad de consumo obedeció a sus ventas al entorno regional o al abasto de las capitales del reino.

Por último, las condiciones de un episodio económico como la feria de San Juan anuda el conjunto de circuitos de circulación interior, tanto regionales como de larga distancia, ratificando nuestra impresión sobre la enorme importancia del evento en la dinámica del mercado 
regional e interno novohispano. Los valores de su tráfico, en correspondencia, reflejan la escala de los intereses en juego: en pocos cargamentos se concentraron más de 237 mil pesos en mercaderías, sumando el promedio más alto despachado por circuito de circulación, esto es, 15 mil pesos por remisión.

Finalmente, la innegable importancia de los despachos dirigidos a "varios destinos" nos obliga a hacer una acotación particular ya que sumó casi un millón de pesos y representó un 30\% del total negociado. En efecto, es probable que este tráfico obedeció, más que a una consignación entre particulares, al negocio de los grandes mayoristas veracruzanos, quienes, a través de sus propios viandantes, colocaban directamente sus mercancías, siguiendo rutas de distribución de mercancías preestablecidas. Los personajes involucrados, así como el carácter genérico de sus despachos, nos hacen pensar en que se trataba de los más poderosos comerciantes del puerto que, sin embargo, debían rendir el derecho a la corporación de sus semejantes de Guadalajara, en tanto penetraran en el territorio jurisdiccional de éstos.

Con independencia de este último caso, los despachos de las mercancías averiadas nos permiten sostener la hipótesis de que la circulación regional estaba inscrita en un tejido de circuitos de amplia longitud, convergente en sus plazas de abasto y divergente en sus rutas de distribución. Así como notamos la vinculación entre el tráfico veracruzano y el norte del reino, es posible postular que la circulación regional de Guadalajara compartía nichos de mercado con el gran trazo del mercado novohispano: la feria de San Juan, por ejemplo, es la evidencia de mayor relevancia. Pero otro tanto merece el tráfico al noroeste, siguiendo la ruta de Guadalajara, Tepic y el puerto de San Blas.

\section{A manera de conclusión}

La erección de los nuevos consulados de comercio, resultado de la política de comercio libre, supuso una transformación profunda del arreglo institucional y económico de los mercados coloniales hispanoamericanos. El declive del monopolio en la Carrera de Indias, que fracturó definitivamente el poder de las corporaciones de Lima y ciudad de México, propició la diversificación de los intereses involucrados en el comercio de importación. En efecto, como resultado de la 
prosperidad regional, o bien como respuesta a las nuevas condiciones institucionales desde Santiago de Chile hasta Guadalajara, entre 1793 y 1795, los consulados americanos recién fundados constituyeron una nueva identidad corporativa de los comerciantes que, en algunos casos, se tradujo en un cambio profundo en el comercio interno de importaciones. En particular, para la Nueva España, la erección de los consulados de Veracruz y Guadalajara, vino a transformar el esquema organizativo del mercado interno de importaciones y crear las condiciones institucionales para el desarrollo de nuevas élites comerciales, cobijadas en sus nuevas corporaciones.

En casos como el de Guadalajara, la coyuntura de prosperidad económica experimentada desde la década de 1770, acompañada de una dinámica espacial del mercado regional, generó circunstancias propicias para una nueva integración económica entre la región y el dinámico mercado interno novohispano, particularmente en su dimensión septentrional. La escala de los negocios creció, y el papel de Guadalajara como centro distribuidor de productos importados aumentó significativamente.

Como no había ocurrido antes, la élite comercial de Guadalajara contó con la oportunidad de dilatar el radio de sus negocios, incrementar su poder corporativo y disputar el control sobre territorios del comercio novohispano, tradicionalmente dominados por los almaceneros de la capital. En particular, el comercio septentrional se convirtió en un campo de discordia: los mayoristas de la capital perdieron la exclusividad del tráfico a distancia, gracias a los despachos directos desde Veracruz, y la intermediación de ciudades comerciales y ferias regionales que diversificaron el intercambio, disminuyendo los costos de transacción a favor de las élites provinciales.

Dos aspectos cobraron especial importancia en la nueva realidad institucional: primero, la fragmentación territorial de la soberanía de las comunidades de comerciantes y; segundo, el nuevo protagonismo de los actores corporativos en un contexto de crisis imperial. En este nuevo sistema de equilibrios y competencia, la cohesión colectiva de las comunidades comerciales fue un factor determinante en el poder de sus nuevas corporaciones. Es por ello que, pese a que estuvieron controladas por minorías de hombres notables imbricados en la red tradicional de poderes regionales, el papel de los consulados como 
actores colectivos no carece de relevancia: no fueron instrumento de una minoría sino herramienta colectiva en manos de una minoría.

La autoridad corporativa descansó, en buena medida, en la capacidad institucional de transformar los costos de transacción privados en institucionales, disminuyendo su peso en los negocios de comerciantes agremiados. Especialmente, los costos derivados de cumplimiento de contratos, los de especificación de derechos de propiedad y los derivados del propio mercado, como la fiscalización y la infraestructura caminera. Pese a su carácter de corporación de Antiguo Régimen, el consulado cumplió un significativo papel en el desarrollo del mercado disminuyendo los costos de transacción y generando condiciones institucionales favorables a los intereses de la élite en él representada.

En este contexto, el estudio de las transformaciones ocurridas en la organización del mercado interno de importaciones y la conformación de actores institucionales nuevos así como la gestión de estos intereses por las élites provinciales constituye una medida de la profundidad del cambio económico en el periodo colonial tardío. 
Cuadro 1: Élite de comerciantes en el cuerpo consular de Guadalajara, 1795-1821

\begin{tabular}{|c|c|c|c|c|c|c|c|c|}
\hline \multirow[t]{2}{*}{$\begin{array}{l}\text { Cargo consular } \\
\text { Comerciante (neriodo activo) }\end{array}$} & \multicolumn{2}{|c|}{$\begin{array}{c}\text { Prior } \\
\text { Pro Ten }\end{array}$} & \multicolumn{2}{|c|}{$\begin{array}{l}\text { Cónsul } \\
\text { Pro Ten } \\
\end{array}$} & $\begin{array}{l}\text { Consi- } \\
\text { liario } \\
\text { Pro Ten }\end{array}$ & \multicolumn{2}{|c|}{$\begin{array}{l}\text { Síndico } \\
\text { Pro Ten } \\
\end{array}$} & \multirow[t]{2}{*}{$\begin{array}{l}\text { Total } \\
\text { Cargos }\end{array}$} \\
\hline & & & & & & & & \\
\hline Juan José Cambero*(1795-1816) & 2 & 2 & 2 & & 1 & & & 7 \\
\hline $\begin{array}{l}\text { Antonio Pacheco Calderón* } \\
\text { (1795-1818) } \\
\text { Juan Manuel Caballero }\end{array}$ & 2 & & & & 1 & 1 & & 4 \\
\hline $\begin{array}{l}\text { (1798-1818) } \\
\text { Martín Gutiérrez Fernández* }\end{array}$ & 1 & 2 & 1 & 1 & & & 1 & 6 \\
\hline $\begin{array}{l}(1797-1818) \\
\text { Antonio Daens Caserta, }\end{array}$ & 1 & 1 & 1 & 2 & & & & 5 \\
\hline $\begin{array}{l}\text { barón de Santa Cruz (1796-1812) } \\
\text { José Ventura García Sancho }\end{array}$ & 1 & 1 & 1 & & 1 & & & 4 \\
\hline $\begin{array}{l}(1805-1819) \\
\text { Gregorio Gómez de la Fuente }\end{array}$ & 1 & & 2 & 1 & 1 & 1 & & 5 \\
\hline$(1797-1814)$ & 1 & & 1 & & 1 & 1 & & 4 \\
\hline $\begin{array}{l}\text { Francisco Cerro (1801-1820) } \\
\text { Eugenio Moreno de Tejada* }\end{array}$ & 1 & & 1 & & 1 & 1 & & 4 \\
\hline$(1795-1803)$ & 1 & & 1 & & 1 & & & 3 \\
\hline José Monasterio* (1795-1802) & 1 & & & 1 & & 2 & & 4 \\
\hline $\begin{array}{l}\text { Juan López Portillo* (1795-1798) } \\
\text { Ángel Antonio Mazón }\end{array}$ & 1 & & & & 1 & & & 2 \\
\hline $\begin{array}{l}\text { (1796-1808) } \\
\text { Manuel Gómez Valleio* }\end{array}$ & & 2 & & & 1 & 1 & & 4 \\
\hline $\begin{array}{l}\text { (1795-1820) } \\
\text { Miguel Sánchez Leñero* }\end{array}$ & & 1 & 1 & & & 1 & & 4 \\
\hline $\begin{array}{l}(1797-1814) \\
\text { Francisco Venancio del Valle }\end{array}$ & & 1 & 1 & & 2 & & & 4 \\
\hline$(1800-1818)$ & & 1 & 1 & & 1 & & 1 & 4 \\
\hline $\begin{array}{l}\text { Manuel del Valle (1799-1817) } \\
\text { Joaquín Gómez del Corral }\end{array}$ & & 1 & 1 & & 1 & 1 & & 4 \\
\hline $\begin{array}{l}\text { (1801-1820) } \\
\text { Juan Francisco Corcuera }\end{array}$ & & 1 & & 2 & 2 & 1 & & 6 \\
\hline $\begin{array}{l}\text { (1804-1816) } \\
\text { Manuel García de Quevedo }\end{array}$ & & & 2 & 1 & 1 & & & 4 \\
\hline $\begin{array}{l}\text { (1804-1820) } \\
\text { Domingo Ibarrondo }\end{array}$ & & & 2 & 1 & & & & 3 \\
\hline $\begin{array}{l}\text { (1801-1817) } \\
\text { Alfonso Sánchez Leñero }\end{array}$ & & & 1 & & 2 & 3 & & 6 \\
\hline $\begin{array}{l}\text { (1797-1818) } \\
\text { Manuel López Cotilla* }\end{array}$ & & & 2 & 2 & 1 & & & 3 \\
\hline $\begin{array}{l}(1796-1810) \\
\text { Ventura Rubio Escudero* }\end{array}$ & & & 1 & 2 & & 3 & & 6 \\
\hline$(1796-1805)$ & & & 1 & 1 & & 1 & & 3 \\
\hline
\end{tabular}




\begin{tabular}{lccccc}
\hline Cargo consular & Prior & Cónsul & $\begin{array}{c}\text { Consi- } \\
\text { liario } \\
\text { Pro Ten }\end{array}$ & $\begin{array}{c}\text { Pro Ten } \\
\text { Pro Ten Pro Ten }\end{array}$ & $\begin{array}{c}\text { Total } \\
\text { Cargos }\end{array}$ \\
\hline Comerciante (periodo activo) & & & & & \\
\hline $\begin{array}{l}\text { Matías Vergara (1800-1816) } \\
\text { José Zumelzu* (1795-1798) }\end{array}$ & 1 & 1 & 1 & & 3 \\
$\begin{array}{l}\text { Vicente Partearroyo } \\
\text { (1799-1805) }\end{array}$ & 1 & & 1 & 1 & 3 \\
$\begin{array}{l}\text { Ignacio de Estrada* } \\
\text { (1795-1798) }\end{array}$ & 1 & & 1 & & 2 \\
Miguel Leñero* (1799-1801) & 1 & 1 & & 2 \\
\hline
\end{tabular}

Relación Cargos de grupo/

Total

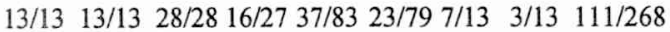

Relativo Cargos de grupo/

Total

$\begin{array}{llllllllll}100 \% & 100 \% & 100 \% & 59 \% & 44 \% & 29 \% & 54 \% & 23 \% & 41 \%\end{array}$

(*) Firmante de la Junta General de Comercio de 1791, promotora de la fundación del Consulado.

Pro $=$ Propietario

Ten $=$ Teniente

\section{Cuadro 2: Organización mercantil del territorio fiscal del Consulado de Guadalajara}

\begin{tabular}{lll}
\hline Territorio económico & Aduanas & Intendencia \\
\hline $\begin{array}{l}\text { Guadalajara y su } \\
\text { hinterland }\end{array}$ & Guadalajara, Colima, Sayula y Ahuacatlán & Guadalajara \\
Puertos marítimos & Veracruz & Veracruz \\
& Acapulco & México \\
& San Blas & Guadalajara \\
Camino de Tierra Adentro & Aguascalientes y San Juan & Guadalajara \\
& Durango, Chihuahua y Cieneguilla & Durango \\
& Saltillo y Monclova & Coahuila \\
& Zacatecas, Fresnillo, Sierra de Pinos y & Zacatecas \\
Minas & Sombrerete & \\
& Charcas & San Luis \\
& Bolaños & Potosí \\
& Cosalá, Real de Sinaloa, Álamos y & Arizpe \\
& San Antonio de la Huerta & \\
& Tepic y San Blas & Guadalajara \\
& Culiacán, Rosario, Arizpe y San Miguel & Arizpe \\
& Horcasitas & \\
\hline
\end{tabular}

Fuente: AGI, Guad. 529-531. 


\section{Cuadro 3: Diputaciones del Consulado de Guadalajara}

\begin{tabular}{lll}
\hline Diputación & Intendencia & Fecha de la instrucción \\
\hline Aguascalientes, Bolaños y Sayula & Guadalajara & \\
Zacatecas y Sombrerete & Zacatecas & \\
Durango y Chihuahua & Durango & 14 de junio de 1796 \\
Tepic & Guadalajara & $1^{\circ}$ de septiembre de 1797 \\
Saltillo & Coahuila & 20 de junio de 1797 \\
Real del Rosario & Arizpe & 14 de febrero de 1801 \\
Santiago Papasquiaro & Arizpe & \\
San Juan de los Lagos & Guadalajara & 15 de octubre de 1807 \\
Colima & Guadalajara & 1809 \\
Arizpe & Arizpe & 1814 \\
\hline
\end{tabular}

Fuente: Villaseñor (1970: 150-151) y Ramírez Flores (1976: 87-92).

\section{Cuadro 4: Despachos desde Veracruz al territorio consular de Guadalajara, 1795-1796}

\begin{tabular}{lrrrr}
\hline Destinos & Guías & Valores \$ & $\%$ & Acumulado \\
\hline Varios destinos no especificados & 13 & 922.146 & 31,0 & \\
Zacatecas & 81 & 391.994 & 13,2 & 44,2 \\
Saltillo & 28 & 293.721 & 9,9 & 54,1 \\
Feria de San Juan & 14 & 235.526 & 7,9 & 62,0 \\
Durango & 48 & 149.377 & 5,0 & 67,0 \\
Guadalajara & 116 & 139.486 & 4,7 & 71,7 \\
Real del Catorce & 32 & 110.494 & 3,7 & 75,4 \\
Chihuahua & 19 & 89.127 & 3,0 & 78,4 \\
Matehuala & 14 & 81.118 & 2,7 & 81,1 \\
Sombrerete & 25 & 47.740 & 1,6 & 82,7 \\
San Luis Potosí & 27 & 41.238 & 1,4 & 84,1 \\
Aguascalientes & 35 & 37.141 & 1,3 & 85,4 \\
Bolaños & 8 & 28.673 & 1,0 & 86,4 \\
Real de Guarisamey & 5 & 27.575 & 0,9 & 87,3 \\
Real del Avinito & 6 & 27.359 & 0,9 & 88,2 \\
Tepic & 7 & 25.183 & 0,8 & 89,0 \\
Real de Álamos & 7 & 24.027 & 0,8 & 89,8 \\
Parral & 4 & 23.340 & 0,8 & 90,6 \\
Sonora & 3 & 17.806 & 0,6 & 91,2 \\
Real de Loreto & 1 & 15.729 & 0,5 & 91,7 \\
Lagos & 4 & 14.200 & 0,4 & 92,1 \\
Etzatlán & 6 & 10.298 & 0,3 & 92,4 \\
Otros destinos especificados & 143 & 215.317 & 7,5 & 100,0 \\
\hline Suma & 503 & 2.753 .298 & 100,0 & \\
\hline
\end{tabular}

Fuente: AGI, Guad. 529, Libro de avería, 1795-1796. 
Cuadro 5: Despachos de Veracruz por
circuitos de circulación interior, 1795-1796

\begin{tabular}{lrrrrr}
\hline Circuitos & Guías & \multicolumn{1}{c}{$\%$} & \multicolumn{1}{c}{ Valores \$ } & \multicolumn{1}{c}{$\%$} & Promedio \$ \\
\hline Tierra Adentro & 310 & 48,0 & 1.198 .029 & 40,3 & 3.847 \\
Minas novohispanas & 91 & 14,0 & 249.891 & 8,4 & 2.746 \\
Feria de San Juan & 15 & 2,3 & 237.371 & 8,0 & 15.825 \\
Guadalajara & 115 & 17,8 & 138.849 & 4,6 & 1.207 \\
Hinterland regional & 52 & 8,0 & 85.077 & 2,8 & 1.636 \\
Haciendas de campo & 15 & 2,3 & 29.024 & 1,0 & 1.935 \\
Minas regionales & 9 & 1,4 & 28.911 & 0,9 & 3.212 \\
Transpacíficos & 10 & 1,5 & 28.896 & 0,9 & 2.890 \\
Novohispano & 6 & 1,0 & 13.410 & 0,4 & 2.235 \\
Varios destinos & 13 & 2,0 & 922.146 & 31,0 & 70.934 \\
Sin dato & 10 & 1,5 & 37.011 & 1,2 & 3.701 \\
\hline Suma & 646 & 100,0 & 2.968 .615 & 100,0 & \\
\hline
\end{tabular}

Fuente: AGI, Guad. 529, Libro de avería, 1795-1796. 
Mapa 1: Destinos del comercio averiado desde Veracruz para el territorio consular de Guadalajara, 1795-1796

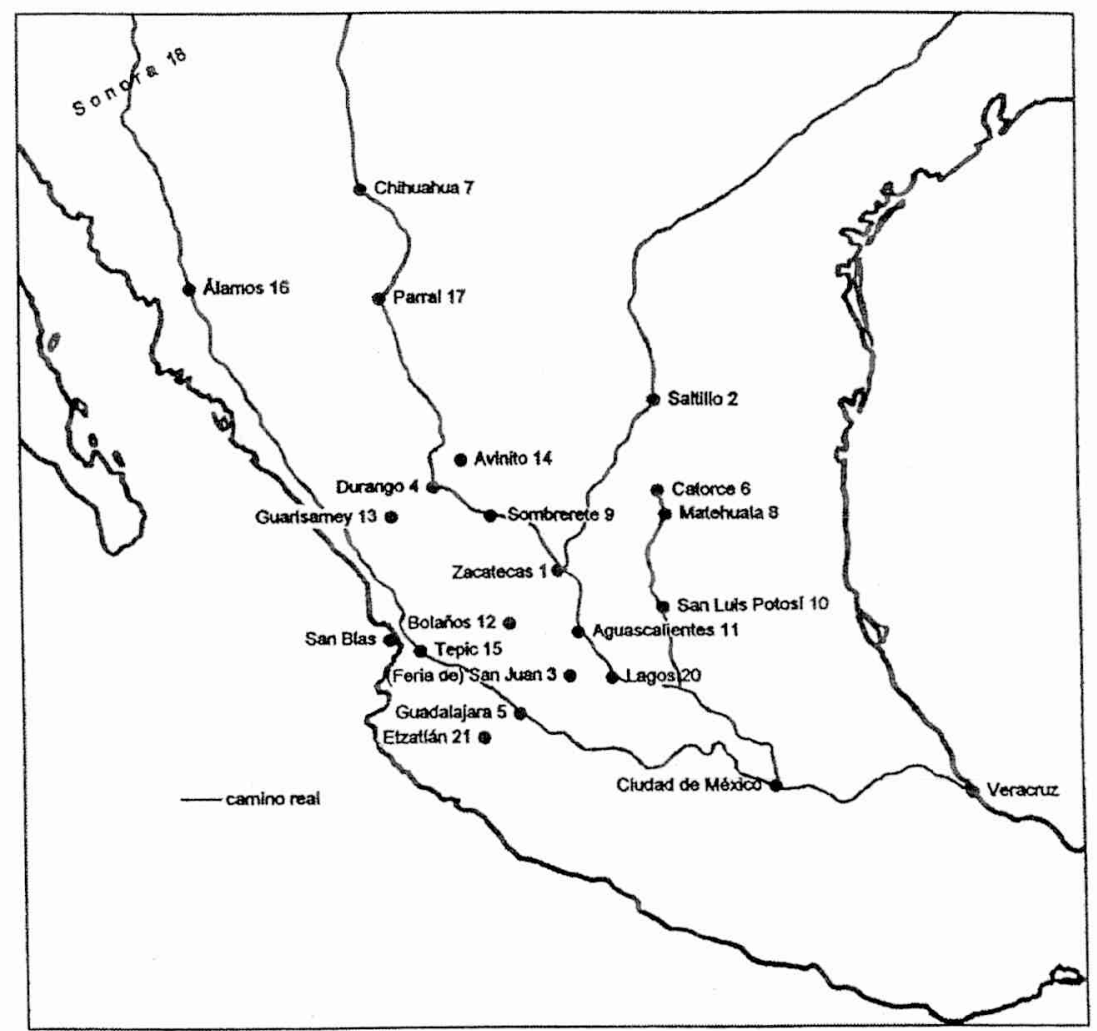

